\title{
An Electrochemical Micro Actuator
}

\author{
M.W. Hamberg* , C. Neagu, J.G.E. Gardeniers, D.J. IJntema** and M. Elwenspoek \\ MESA Research Institute, University of Twente, P.O. Box 217, 7500 AE Enschede, The Netherlands \\ * present address: Industrial Microelectronics Centre, Kista, Sweden \\ ** present address: Philips Research Lab., Eindhoven, The Netherlands
}

\begin{abstract}
In this paper an investigation of the feasibility of a new electrochemical micro actuator is presented. The actuator is fabricated using silicon micro-machining techniques. A gas pressure is generated by electrolysis of an aqueous electrolyte solution. The build up pressure is used to change the deflection of a membrane. The actuator has three states: the electrolysis state, in which the pressure is built up; the passive state, in which the circuit is open and the pressure is maintained; and the pressure reduction state, in which the electrodes are short-circuited in order to reduce the pressure. The advantage of this type of actuation is a low energy consumption. The power is required during pressure build up and to change the states.
\end{abstract}

\section{Introduction}

The principle of electrochemical actuation is based on reversible reactions where gases are produced by means of electrolysis. In a closed system the build up pressure caused by gas production can be used for membrane deflection. The chemical reaction can be reversed by short-circuiting the electrodes or by reversing the polarity of the applied power supply, so that the obtained pressure reduces and the deflection of the membrane decreases. Under open-circuit conditions the pressure in the actuator will, in principle, be maintained, as well as the deflection state of the membrane. This means that no energy is required to keep this state in contrast to conventional actuation principles e.g. electrostatic, piezoelectric or thermo-pneumatic.

Relatively large pressures can be created, therefore promising applications can be found in micro fluidhandling e.g. pumps and active valves.

Electrochemical macro actuators were reported for the first time by H. Janocha in 1988 [1]. These actuators were made in a steel case with a size of at least $5 \times 5 \times 5$ $\mathrm{cm}^{3}$. Two principles were used, electrolysis of water and solid/gas reactions. The latter principle is also described by W. Kempe [2].

In this paper an electrochemical micro actuator fabricated by silicon micro machining is presented. Actuator design, fabrication process and results of performance test are shown.

\section{Theory}

\subsection{Electrochemical reactions}

Depending on requirements and applications several electrochemical reactions can be chosen [3] and the actuator can be operated with different results. The choice of the electrodes and ions in the solution determines the kind of gas(es) which evolve at the electrode(s). To have the reaction reversible and only one type of gas evolving, viz. oxygen, a solution of copper sulphate in combination with a platinum $(\mathrm{Pt})$ and a copper $(\mathrm{Cu})$ electrode was chosen. The platinum electrode acts as a catalyst for the oxygen formation. The three states of the actuator are treated in more detailed below:

A. Electrolysis state: The half-cell reactions are as follows:

$$
\begin{aligned}
& \text { anode }(\mathrm{Pt}): 2 \mathrm{H}_{2} \mathrm{O}_{(\mathrm{l})} \Rightarrow \mathrm{O}_{2(\mathrm{~g})}+4 \mathrm{H}_{(\mathrm{aq})}^{+}+4 \mathrm{e}^{-} \\
& \text {cathode }(\mathrm{Cu}): \mathrm{Cu}^{2+}{ }_{(\mathrm{aq})}+2 \mathrm{e}^{-} \Rightarrow \mathrm{Cu}_{(\mathrm{s})}
\end{aligned}
$$

The overall cell reaction for $\mathrm{O}_{2(\mathrm{~g})}$ production is

$2 \mathrm{H}_{2} \mathrm{O}_{(\mathrm{l})}+2 \mathrm{Cu}^{2+}{ }_{(\mathrm{aq})} \Leftrightarrow \mathrm{O}_{2(\mathrm{~g})}+4 \mathrm{H}^{+}{ }_{(\mathrm{aq})}+2 \mathrm{Cu}_{(\mathrm{s})}$

with an equilibrium potential of $0.89 \mathrm{~V}$

During electrolysis, oxygen gas evolves at the platinum electrode while copper ions precipitate at the copper electrode. The time of building up the pressure depends on different variables which affect the electrode reaction rate [4]: electrode material, surface area, geometry, surface condition; ionic and gas diffusion, convection; electrolyte concentration (some oxygen will dissolve in water depending on the pressure of oxygen); external effects (temperature, pressure); electrical parameters (charge, over potential, impedance).

B. Passive state: Under open circuit conditions the build up pressure is maintained. But this "steady-state" can be disturbed by leakage out of the system or back reactions at the copper electrode (see below). These, of course, occur also during pressure build up. 
C. Pressure reduction state: This can be done by externally short-circuiting of the cell or by reversing the applied current. The reverse reaction reduces the generated oxygen to water and solid copper to copper ions.

Two parasitic reactions can be expected to take place at the copper electrode:

i) production of hydrogen gas:

$$
2 \mathrm{H}^{+}(\mathrm{aq})+2 \mathrm{e}^{-} \Rightarrow \mathrm{H}_{2}(\mathrm{~g})
$$

If this reaction is combined with the $\mathrm{O}_{2}$ production reaction at the $\mathrm{Pt}$ electrode, the equilibrium potential is $1.23 \mathrm{~V}$. When the voltage across the cell is larger than this value hydrogen evolution is expected. Besides on the voltage, it depends on the nature of the electrode which reaction will be more favourable (prominent): the unwanted reaction (4) or the wanted reaction (2). E.g. the exchange current density for reduction of hydrogen ions is about 200 times slower on copper than on platinum [5].

ii) copper oxide formation:

$$
4 \mathrm{Cu}_{(\mathrm{s})}+\mathrm{O}_{2(\mathrm{~g})} \Rightarrow 2 \mathrm{Cu}_{2} \mathrm{O}_{(\mathrm{s})}
$$

with an equilibrium potential of $0.76 \mathrm{~V}$.

This spontaneous reaction leads not only to a blocking oxide layer which affects the electrical characteristics of the cell and the kinetics of reaction (2), but also reduces the oxygen gas pressure and therefore the efficiency of the actuator.This reaction will ultimately reduce the lifetime of the cathode. To reduce this effect, the copper electrode is protected from oxygen by using a permselective membrane $\left(\right.$ Nafion ${ }^{\circledR}$ [6]). Many positive ions and polar compounds are permeable for this membrane, but negative ions and non-polar compounds like oxygen gas are impermeable, so that the current loop during electrolysis is closed [7].

\subsection{Membrane deflection}

The relation between membrane deflection and applied pressure is modelled using the theory for small and large deflections of flat and corrugated membranes $[8,9]$. For small deflections the relation between pressure and deflection is linear (only bending of the membrane). The non-linearity which occurs for large deflections is the result of tensile stress caused by stretching of the membrane. If a large initial (residual) stress is present in the membrane, the effect of bending can be neglected and a new first order term is introduced. For a flat, square membrane with thickness $h$, length $2 a$, Young's modulus $E$, Poisson's ratio $v$ and initial stress $\sigma$ the relation between the pressure difference $P$ over the membrane and the corresponding centre deflection $y$ is described by $[10]$ :

$$
P=\frac{3.41 \sigma h}{a^{2}} y+\frac{E h}{a^{4}} \frac{1.98(1-0.295 v)}{1-v} y^{3}
$$

In order to increase the linear range, to obtain large deflections and to reduce the initial stress [11] corrugated membranes can be used.

\section{Experimental}

\subsection{Design and realisation}

The actuator is made by standard micro machining technology. It consists of an arrangement of two electrodes in a sealed cavity filled with electrolyte. This has been realized by bonding two processed silicon wafers together (see Figure 1). On one wafer the metal electrodes are deposited by sputtering; micro machined access holes are used to fill the cavity. The electrical contacts, which are on the backside of this wafer, are
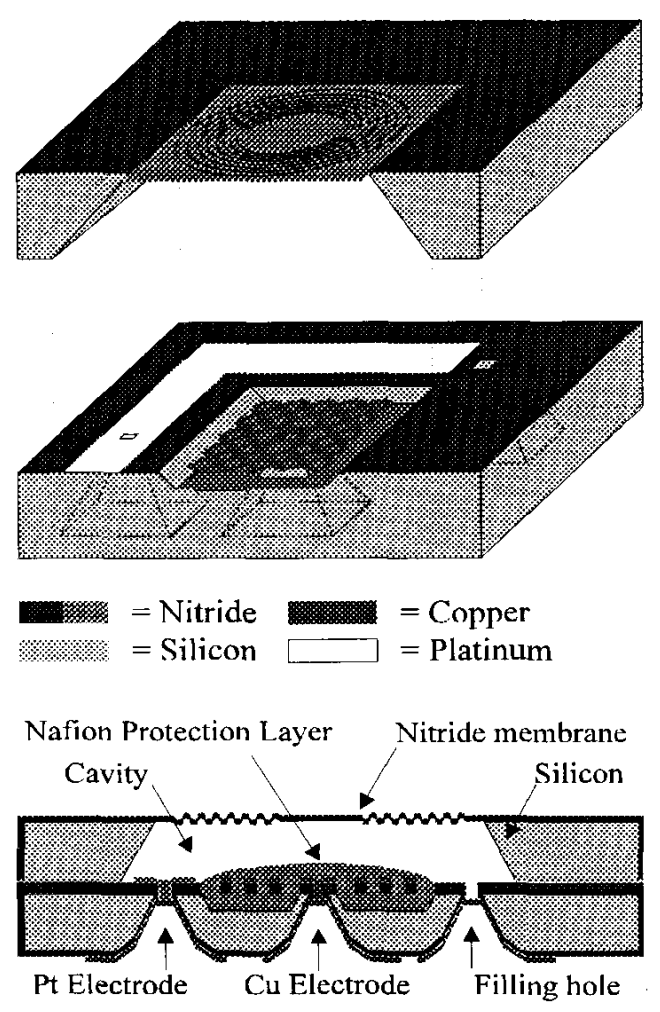

Figure 1. Schematic design of the micro machined electrochemical actuator. The size is $2 \times 2 \times 0.8 \mathrm{~mm}^{3}$. 
connected with the electrodes on the front side through etched holes

To prevent oxygen reduction at the copper electrode, this electrode was protected with a spin-coated Nafion ${ }^{\circledR}$ laycr. But the major problem of using $\mathrm{Nafion}^{\circledR}$ in micromechanical applications is its adhesion. Thus copper clectrode is made as a perforated standing table as an attempt to solve this problem. Such a design should also compensate the stresses developing in the Nafion ${ }^{\circledR}$ layer during drying and after soaking in the electrolyte, the latter is known to lead to relatively large volume changes in the polymer [6].

The second wafer contains the cavity with a $1.2 \times 1.2$ $\mathrm{mm}^{2}$ silicon nitride membrane of $1 \mu \mathrm{m}$ thickness. The cavity is filled by immersing the wafer package under the electrolyte in a vacuum chamber. For tests presented here, however, bonding and sealing where done by adhesive.

\subsection{Performance measurements}

First, the deflection of a flat silicon nitride membrane was measured using air pressure. The measurements were performed with a stylus profilometer, Sloan DEKTAK, and are shown in Figure 2. The analytical simulation, equation (6), with $E=3 \mathrm{GPa}, v=0.3$, and $\sigma=100 \mathrm{MPa}$ is also plotted in Figure 2, as a solid line. The experimental data is in good agreement with theory. From this "calibration curve", the volume of the cavity and measurements of the deflection during oxygen pressure building up the amount of gas produced can be calculated.

It was observed that for a positive voltage $(\leq 2 \mathrm{~V})$ and a current of about $1 \mathrm{~mA}$ a huge production of oxygen gas (bubbles) occurs, so that flat membranes are

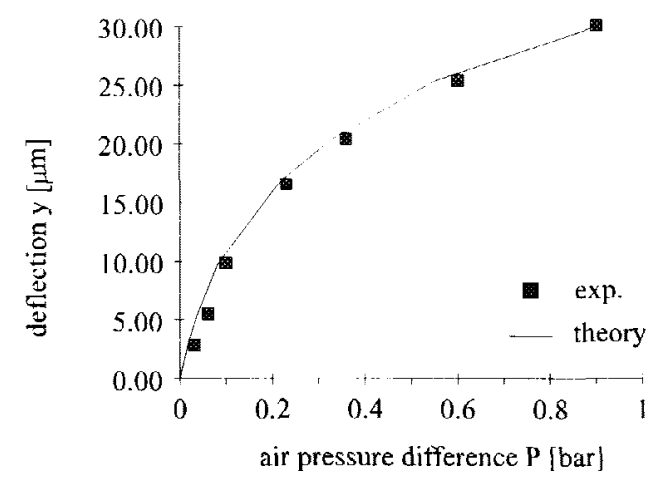

Figure 2. Comparison of simulated and measured deflection of a square, flat membrane as function of pressure difference. blown up within a few seconds. In order to study the behaviour of the actuator, currents below $50 \mu \mathrm{A}$ were used to have a slower and more controllable gas production (Figure 3).

The deflection of the membrane was sensed using an atomic force microscope set-up in order to investigate the dynamic behaviour. The deflection of the membrane causes displacement of the force sensor, which is detected using the optical beam deflection technique; the atomic force microscope is described in more detail elsewhere [12]. The maximum deflection which can be measured by the atomic force microscopc is ca. $10 \mu \mathrm{m}$, thus for larger deflections of the membranc, c.g. (phase stepping) interferometry technique can be uscd.

The variation of the voltage across the electrochemical cell (Vcell) and the deflection of the membrane were simultaneously measured using a $1 \mathrm{M} \Omega$ input impedance recorder. All measured deflections are in the linear range of the pressure-deflection curve (see Figure 2), so the oxygen pressure is proportional with the measured deflection.

\section{Results and Discussion}

For an applied constant DC current of $2 \mu \mathrm{A}$ the voltage across the actuator cell increased asymptotically to a value of $1.1 \mathrm{~V}$ within a few minutes. However, after 20 minutes still no oxygen production could be observed, although the voltage was larger than the equilibrium potential of $0.89 \mathrm{~V}$ (see section 2). For this current theoretically an $\mathrm{O}_{2}$ production rate of $5 \cdot 10^{-12} \mathrm{~mol} \mathrm{~s}^{-1}$ is expected. Assuming that the cell is absolutely gas-tight, we can explain the absence of $\mathrm{O}_{2}$ bubbles by the diffusion of $\mathrm{O}_{2}$ through the Nafion ${ }^{\circledR}$ and its subsequent reduction at the $\mathrm{Cu}$ electrode, according to reaction (5) Reported values for the diffusion coefficient of $\mathrm{O}_{2}$ through Nafion ${ }^{(\mathbb{B})}$ films range from $1 \cdot 10^{-11}$ to $2 \cdot 10^{-10}$

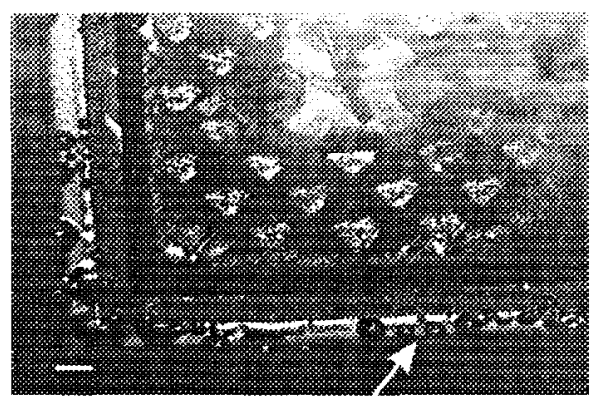

Figure 3. Image of the actuator seen through the silicon nitride membrane of l am thickness. The arrow points at the bubbles of oxygen gas which evolve at the platinum electrode; bar is $0.1 \mathrm{\mu m}$. 
$\mathrm{m}^{2} \mathrm{~s}^{-1}[13,14]$. If the Nafion ${ }^{\circledR}$ film thickness is at least $1 \mu \mathrm{m}$, the copper electrode area is $0.8 \mathrm{~mm}^{2}$ and the maximum $\mathrm{O}_{2}$ concentration difference between both sides of the Nafion ${ }^{\circledR}$ film is $103 \mathrm{~mol} \mathrm{~m}^{-3}$ (which is approximately the maximum solubility of oxygen in the solution under these conditions), we estimate an oxygen loss rate of ca. $8 \cdot 10^{-12} \mathrm{~mol} \mathrm{~s}^{-1}$. Since this is higher than the expected production rate, it is not surprising that we do not observe oxygen production. It has to be mentioned that these are just estimations since we do not exactly know the active area of the copper electrode nor the thickness of the Nafion ${ }^{\mathbb{B}}$ film.

For a current of $5 \mu \mathrm{A}$ the generation of gas pressure (curve $\mathrm{AB}$ ) and its reduction by short cutting the cell circuit (point B) are shown, as a dashed line in Figure 4 (top). Besides, the variation of Vcell is shown with a continuous line. Figure 4 (bottom) shows the open circuit mode under the same conditions. Curve $\mathrm{AC}$ is the building up of the pressure and at point $C$ the circuit is opened. For a deflection of $1.25 \mu \mathrm{m}$ the obtained pressure is $20 \mathrm{mbar}$ and the building time is $100 \mathrm{~s}$ for 5 $\mu \mathrm{A}$. At points $\mathrm{B}$ and $\mathrm{C}$ the pressure is $27 \mathrm{mbar}$ for 1.71 $\mu \mathrm{m}$ and the time is $180 \mathrm{~s}$.
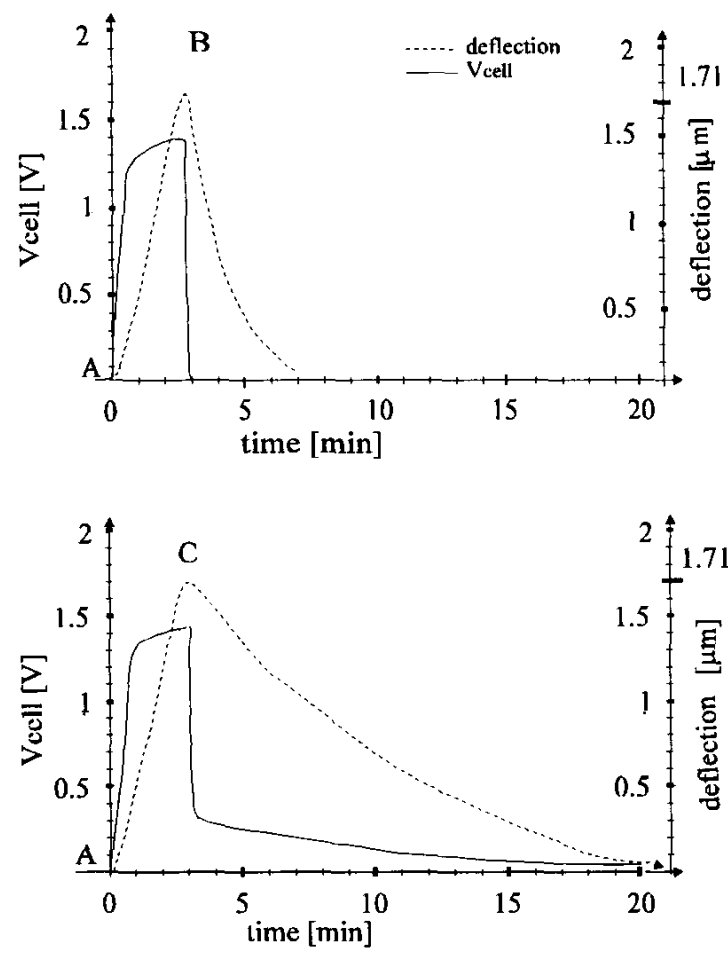

Figure 4. The voltage across the electrochemical cell (Vcell) and the deflection of the membrane, in time. The applied constant current is $5 \mu \mathrm{A}$. In point B the cell is short-circuited. In point $C$ the cell is opened.
If the applied current is increased to $10 \mu \mathrm{A}$, the reactions have the same general behaviour but are faster. This can be seen in Figures 5 (top and bottom). As in Figure 4 the curve $A B$ is the building up of pressure and in the point $B$ the pressure is reduced by short-circuiting the electrodes, and in point $\mathrm{C}$ the circuit is opened. For the same deflection of $1.25 \mu \mathrm{m}$, the obtained pressure is $20 \mathrm{mbar}$ but the building time is $42 \mathrm{~s}$ for $10 \mu \mathrm{A}$. At points $\mathrm{B}$ and $\mathrm{C}$ the pressure is 33.4 $\mathrm{mbar}$ for $2 \mu \mathrm{m}$ and the time is $60 \mathrm{~s}$.

Theoretically the oxygen production rate for a current of $5 \mu \mathrm{A}$, i.e. the situations of Figure 4, is $12.5 \cdot 10^{-12} \mathrm{~mol} \mathrm{~s}^{-1}$ From the measured data we derive a pressure increase rate of $15 \mathrm{~Pa} \mathrm{~s}^{-1}$. As the volume of the cell is about 0.5 $\mathrm{mm}^{3}$, the experimentally observed oxygen production rate is ca. $5 \cdot 10^{-12} \mathrm{~mol} \mathrm{~s}^{-1}$. Since the difference between this value and the theoretical one can be considered to be the oxygen removal rate by diffusion through the Nafion ${ }^{B}$ and reaction at the copper electrode (see above), we now have a possibility to estimate the diffusion coefficient of $\mathrm{O}_{2}$ through the Nafion ${ }^{\circledR}$ film. With the assumptions mentioned before we arrive at a diffusion coefficient of ca. $510^{-12} \mathrm{~mol} \mathrm{~s}^{-1}$, which is
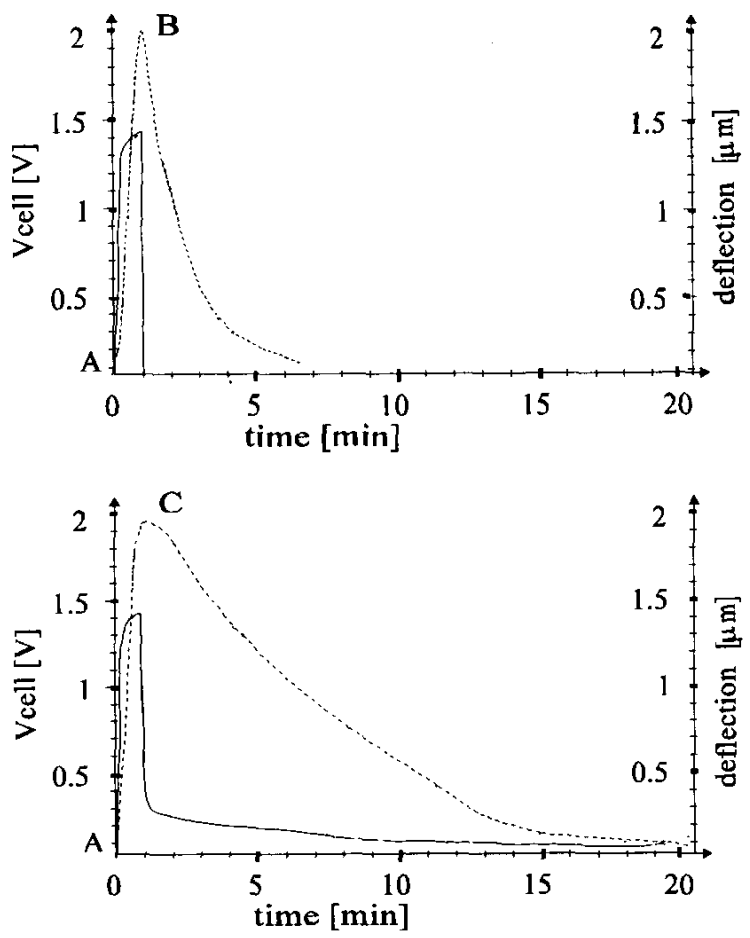

Figure 5. The variation in time of the voltage across the electrochemical cell (Vcell) and the deflection of the membrane for an applied current of $10 \mu \mathrm{A}$. In point $B$ the cell is short-circuited. In point $C$ the circuit is opened 
in the range of the reported values.

Table I shows the time constants $\tau$ for the decrease of the deflection $d$ (i.e. oxygen pressure) as a function of time $t$, where the time dependence is assumed to be of the following form:

$$
d=d_{0} \exp (-t / \tau)
$$

\begin{tabular}{|l|c|c|c|c|}
\hline Figure & 4 top & 4 bottom & 5 top & 5 bottom \\
\hline$\tau /$ sec. & 96 & 348 & 72 & 348 \\
\hline
\end{tabular}

Table 1 . The time constants $\tau$ for the oxygen gas pressure decay.

It can be seen that the time constants for Figures 4 and 5 top are slightly different, and for Figure 4 and 5 bottom, respectively, are the same, as expected. As discussed above, the pressure decrease is probably caused by diffusion of $\mathrm{O}_{2}$ through the Nafion and reduction at the copper electrode.

The decrease of the pressure in Figures 4 and 5 (bottom) points out the importance of a gas/liquid-tight system. Leakage's alter not only the pressure, but also have consequences for the reversibility and the number of cycles of the actuator. Currently the protection of the copper electrode is not very good, therefore further investigation and an optimisation of the electrodes and electrolyte will be done.

\section{Conclusion}

The design, fabrication and operation of a new micro machined electrochemical actuator are presented. Using as little as $7 \mu \mathrm{W}$ for $100 \mathrm{~s}$, a pressure of 20 mbar was obtained which deflects a flat membrane over $1.25 \mu \mathrm{m}$. For a slightly more power, the pressure is built up faster and by using a corrugated membrane larger deflections can be obtained. Although not all of the processes occurring in the device are completely understood, and the design of the actuator is far from optimal, the first results demonstrate the feasibility of this micro actuator.

\section{Acknowledgements}

The authors thank Erwin Berenschot and Kees van der Werf for their technical assistance, Prof. Dr. E.L. Greve and $\mathrm{M}$. Blok for fruitful discussions. This research is supported by the Dutch Organization for Scientific Research NWO and the Academic Medical Centre (AMC) Amsterdam.

\section{References}

[1] H. Janocha, "Neue Aktoren", Proc. Actuator 88, Bremen, June 1988, p.389.

[2] W. Kempe, W. Schapper: "Electrochemical actuators", Proc. Actuator 90, Bremen, 1990, p. 162.

[3] H. Janocha, "Aktoren", grundlagen und anwendungen, Springer-Verlag, 1992.

[4] A. J. Bard, L. R. Faulkner, Electrochemistry methods: fundamentals and applications, John Wilcy \& Sons, 1980.

[5] P. H. Rieger, Electrochemistry, Prentice-Hall, Inc., 1987, Chapter 5.

[6] Nafion ${ }^{\circledR}$ is a E. I. du Pont de Nemours \& Co., Inc., registered trademark; product catalogue no. 27,470-4.

[7] W. G. F. Grot, "Nafion ${ }^{\circledR}$ as a separator in electrolytic cells", The Electrochem. Soc. meeting, Boston, May, 1986.

[8] M. di Giovanni, Flat and corrugated diaphragm design handbook, Marcel Dekker Inc., New York, U.S.A., 1982.

[9] H. Jerman, "The fabrication and use of micro machined corrugated silicon diaphragms", Sensors and Actuators A21-23, 1990, p.988.

[10] J. Y. Pan, P. Lin, F. Maseeh, S. D. Senturia, "Verification of FEM analysis of load-deflection methods for measuring mechanical properties of thin films", Techn. Digest IEEE Solid-State Sensors Workshop, Hilton Head Island, U.S.A., June 1990, p.70.

[11] V. L. Spiering, S. Bouwstra, J. F. Burger, M. Elwenspoek, "Membranes fabricated with a deep single corrugation for package stress reduction and residual stress relief', $J$. Micromech. Microeng., 3, 1993, p.243. [12] K. O. v.d. Werf, C. A. J. Putman, B. G. de Grooth, F. B. Segerink, E. H. Schipper, N. F. van Hulst, J. Greve, Compact stand-alone atomic force microscope, Rev. Sci. Instrum. 64, 1993, p. 2892.

[13] D. R. Lawson, L. D. Whiteley, C. R. Martin, M. N. Szentirmay, J.I. Song, "Oxygen reduction at Nafion film-coated platinum electrodes: Transport and kinetics", J. Electrochem. Soc. 135 (1988) p. 2247.

[14] Z. Ogumi, T. Kuroe, Z. Takehara, "Gas permeation in SPE method. II. Oxygen and hydrogen permeation through Nafion", $J$. Electrochem. Soc. 132 (1985) p. 2601. 